\title{
Nitric oxide treatment for fulminant pulmonary hypertension
}

\author{
K G Allman, J D Young, J E Stevens, L N J Archer
}

\begin{abstract}
A 3 year old child with known pulmonary haemosiderosis suffered acute circulatory collapse secondary to raised pulmonary vascular resistance. Nitric oxide inhalation produced a profound improvement in circulatory parameters and gaseous exchange. Nitric oxide may have a therapeutic role in acute pulmonary hypertensive crisis.

(Arch Dis Child 1993; 69: 449-450)
\end{abstract}

Inhaled nitric oxide is a potent and selective pulmonary vasodilator, which has recently been used to treat persistent pulmonary hypertension of the newborn. We report a case where right ventricular function was markedly improved by nitric oxide inhalation in a 3 year old with idiopathic pulmonary haemosiderosis and pulmonary hypertension.

\section{Case report}

A 3 year old Asian boy weighing $15 \mathrm{~kg}$ was admitted to hospital with a two day history of increasing respiratory distress. Twelve months previously a diagnosis of idiopathic pulmonary haemosiderosis had been made after open lung biopsy. At that time electrocardiography and cardiac ultrasound imaging had shown a degree of right ventricular hypertrophy and raised pulmonary arterial pressure.

On examination he was tachypnoeic with expiratory wheeze, apyrexial, and had early finger clubbing. He was admitted to the ward for observation and bronchodilator treatment. Twelve hours later he had a large (approximately $150 \mathrm{ml}$ ) haemoptysis followed by progressive deterioration of gas exchange. He was therefore transferred to the paediatric intensive care unit for artificial ventilation.
Initially arterial oxygenation $\left(\mathrm{PaO}_{2}\right)$ was maintained between $8-10 \mathrm{kPa}$ with $100 \%$ oxygen and airway pressures of $32 / 5 \mathrm{~cm} \mathrm{H}_{2} \mathrm{O}$. However, after 24 hours he became acutely hypoxic, hypotensive, and bradycardic. His blood pressure decreased from 82 to $40 \mathrm{~mm}$ $\mathrm{Hg}$ systolic, central venous pressure increased from 16 to $22 \mathrm{~mm} \mathrm{Hg}$, and $\mathrm{PaO}_{2}$ decreased to $4.6 \mathrm{kPa}$. He required repeated intravenous boluses of adrenaline to maintain adequate systemic perfusion and oxygenation.

Echocardiography performed at this time showed severe right ventricular dilatation with a peak tricuspid regurgitation velocity of 3.77 $\mathrm{m} / \mathrm{sec}$. Using the modified Bernoulli equation and the measured mean central venous pressure this suggested a suprasystemic right ventricular peak pressure of $73 \mathrm{~mm} \mathrm{Hg}$. Right and left ventricular performance was poor.

After careful discussion with the parents a trial of nitric oxide was initiated. Nitric oxide, supplied as 2000 parts per million (ppm) in nitrogen, was instilled via a precision rotameter into the inspiratory limb of the ventilator circuit to give a final calculated inspired concentration of $40 \mathrm{ppm}$. Direct measurement of nitric oxide was not possible at the time, but subsequent tests on a similar system have revealed the calculated inspired nitric oxide concentration to be accurate to within $10 \%$.

Within five minutes there was a dramatic improvement in clinical condition; oxygenation increased and systemic pressures stabilised (see table). A repeat cardiac echo now showed considerable improvement in right ventricular dilatation and function, with a calculated right ventricular peak pressure of $39 \mathrm{~mm} \mathrm{Hg}$.

The nitric oxide was reduced to $32 \mathrm{ppm}$, and over the subsequent 48 hours it proved possible to reduce the fractional inspired oxygen $\left(\mathrm{FIO}_{2}\right)$ to $0 \cdot 5$. Over the next 48 hours the
John Radcliffe

Hospital, Oxford

OX3 9DU, Nuffield

Department of

Anaesthetics

K G Allman

J D Young

Paediatric Intensive

Care

J E Stevens

Department of

Paediatrics

L N J Archer

Correspondence to: Dr Allman.

Accepted 1 June 1993

Patient characteristics before and after nitric oxide

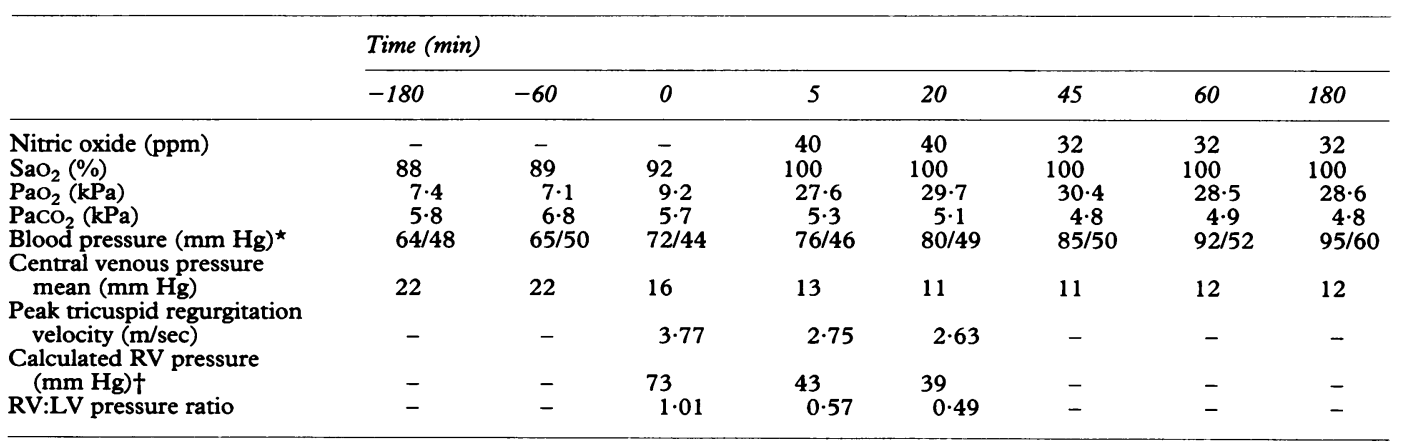

$\mathrm{FiO}_{2} \quad 1 \cdot 0$ and ventilation pressures $34 / 5 \mathrm{~cm} \mathrm{H}_{2} \mathrm{O}$.

$\star$ Right radial arterial pressure.

†Modified Bernoulli equation.

$\mathrm{SaO}_{2}=$ oxygen saturation; $\mathrm{PaO}_{2}=$ arterial oxygen tension; $\mathrm{PaCO}_{2}=$ arterial carbon dioxide tension; $\mathrm{LV}=$ left ventricular; $\mathrm{RV}=$ right ventricular. 
nitric oxide was slowly weaned and the $\mathrm{FiO}_{2}$ gradually reduced to $0 \cdot 3$. The peak methaemoglobin level measured was $2 \cdot 8 \%$ on day two.

Eight days after admission to intensive care, however, he suffered a further severe pulmonary haemorrhage. Nitric oxide was again instituted at parental request, but after an initial improvement hypotension and hypoxia supervened despite the addition of intravenous adrenaline and phentolamine. He died 10 hours later.

\section{Discussion}

Idiopathic pulmonary haemosiderosis is a rare disorder of childhood characterised by recurrent episodes of bleeding into the lungs. ${ }^{1}$ This in turn causes anaemia, pulmonary fibrosis, and progressive pulmonary hypertension. It may present as either acute pulmonary bleeding or as progressive breathlessness.

Nitric oxide is a potent endogenous vasodilator produced by vascular endothelium. ${ }^{2}$ It is rapidly bound and inactivated by haemoglobin (producing methaemoglobin) and when added to inspired gases causes localised pulmonary vasodilatation without systemic effects. It has recently been shown to be effective in treating persistent pulmonary hypertension of the newborn, ${ }^{3}$ as well as pulmonary hypertension associated with congenital heart defects ${ }^{4}$ and adult respiratory distress syndrome. ${ }^{5}$

This child was known to have a degree of raised pulmonary vascular resistance. It is likely that this was compounded by hypoxia and acidosis to produce profound vasoconstriction of the pulmonary vascular tree. The ensuing right ventricular dilatation and failure would cause severe systemic circulatory embarrassment.

Conventional vasodilators have been used in this situation but are limited by their systemic effects. Inhaled nitric oxide is rapidly bound to haemoglobin and appears to be devoid of systemic vasodilator action. Furthermore, nitric oxide will have an effect only on ventilated areas of lung and thereby should improve rather than disrupt ventilation-perfusion matching. It is interesting to note that after starting nitric oxide not only did oxygenation improve, but carbon dioxide levels decreased, despite an unchanged minute ventilation. This would suggest a reduction in physiological deadspace.

Nitric oxide can only be a short term adjuvant treatment, but may find a role in reversing critical hypoxic pulmonary vasoconstriction. In low doses (up to $20 \mathrm{ppm}$ ) it appears to be safe for up to several weeks, ${ }^{4}$ but methaemoglobin levels should be monitored closely. Ideally the inspired nitric oxide and nitrogen dioxide concentrations should be monitored. 1 Soergel KH, Sommers SC. Idiopathic pulmonary 32: 499-511.

2 Moncada S, Palmer RMJ, Higgs EA. Nitric oxide: physiology, pathophysiology, and pharmacology. Pharmacol Rev 1991; 43: 109-42.

3 Roberts JD, Polaner DM, Lang P, Zapol WM. Inhaled nitric oxide in persistent pulmonary hypertension of the newoxide in persistent pulmonary
born. Lancet 1992; 340: 818-9.

4 Haydar A, Mauriat P, Pouard P. Inhaled nitric oxide for postoperative pulmonary hypertension in patients with congenital heart defects. Lancet 1992; 340: 1545

5 Rossaint R, Falke KJ, Lopez F, Slama K, Pison U, Zapol WM. Inhaled nitric oxide for the adult respiratory distress syndrome. $N$ Engl $f$ Med 1993; 328: 399405.

\title{
Can we improve diabetes care in schools?
}

\author{
M A Tatman, D N Lessing
}

\begin{abstract}
Results of a questionnaire study showed that parents were dissatisfied with school care of their children's diabetes and with teachers' knowledge of diabetes. Parents were more satisfied with support in school if a paediatric diabetes liaison service was provided rather than an adult one.

(Arch Dis Child 1993; 69: 450-451)
\end{abstract}

Epidemiology and Biostatistics Unit, Institute of Child Health, London

M A Tatman

Community Health Unit, Upton Hospital, Albert Street, Slough SL1 2BJ

D N Lessing

Correspondence to: Dr Lessing.

Accepted 25 June 1993
Surveys of teachers ${ }^{12}$ and parents $^{34}$ have revealed problems with teachers' knowledge of diabetes. A national study of parents' satisfaction with diabetes care in the first year after their child's diagnosis found $37 \%$ were dissatisfied with school care and $50 \%$ were concerned about teachers' knowledge. ${ }^{5}$ We used information from that study to examine services available to schoolchildren, comparing paediatric and adult diabetes liaison services with respect to parental satisfaction with school care.

\section{Method}

Of the 469 (92\%) parents returning questionnaires, 351 answered the questions on school. Information on each child's place of residence hospital, and paediatrician ${ }^{5}$ was used to identify the service available to the child in the year after diagnosis (1988-9). The liaison service then covering each health district was identified in the British Diabetic Association (BDA)/Royal College of Nursing Directory of nurses with a special interest in diabetes (January 1989). If necessary the type or catchment area of the liaison service then provided was identified by the current liaison nurse.

Classifying children into those covered by adult and those covered by paediatric services (paediatric home care teams covering diabetes, paediatric diabetes nurse specialists, and paediatric diabetes health visitors) was straightforward for the $87 \%$ who were treated in their home district. Children treated outside their home district were classified according to 